TI 2013-080/I

Tinbergen Institute Discussion Paper

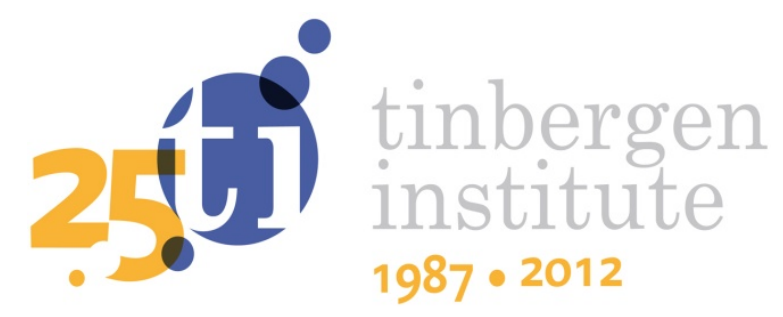

\title{
The Structure of Firm-Specific Labour Unions
}

\author{
Thorsten Upmann' \\ Julia Mül/er²
}

1 University Duisburg-Essen

2 Erasmus School of Economics, Erasmus University Rotterdam, and Tinbergen Institute. 
Tinbergen Institute is the graduate school and research institute in economics of Erasmus University Rotterdam, the University of Amsterdam and VU University Amsterdam.

More TI discussion papers can be downloaded at http://www.tinbergen.nl

Tinbergen Institute has two locations:

Tinbergen Institute Amsterdam

Gustav Mahlerplein 117

1082 MS Amsterdam

The Netherlands

Tel.: +31(0)205251600

Tinbergen Institute Rotterdam

Burg. Oudlaan 50

3062 PA Rotterdam

The Netherlands

Tel.: +31(0)10 4088900

Fax: $+31(0) 104089031$

Duisenberg school of finance is a collaboration of the Dutch financial sector and universities, with the ambition to support innovative research and offer top quality academic education in core areas of finance.

DSF research papers can be downloaded at: http://www.dsf.nl/

Duisenberg school of finance

Gustav Mahlerplein 117

1082 MS Amsterdam

The Netherlands

Tel.: +31(0)20 5258579 


\title{
The Structure of Firm-Specific Labour Unions
}

\author{
Thorsten Upmann*
}

\author{
Julia Müller
}

March 17, 2013

\begin{abstract}
In this paper we investigate trade union formation. To this end we apply a model with two types of labour where both groups decide on whether they prefer to be represented by either two independent craft-specific (professional) labour unions or by a joint (encompassing) labour union. Applying the asymmetric Nash bargaining solution, we find that it is beneficial for at least one group of labourers to resist a unification and to form instead its own independent labour union - and in some cases even both groups are worse off under the umbrella of a joint union. Consequently, a joint union must be considered as a rather unstable institution. As a mirror image, profits are lower if the firm bargains with two independent craft unions. This explains why employers vehemently oppose recent split offs of some occupational groups from existing unions and from stipulated tariff unions.
\end{abstract}

Keywords: trade-union formation, wage-employment bargains, Nash bargaining solution, encompassing and craft-specific labour unions, trade union merger

JEL classification: C78, J31, J41, J51

\footnotetext{
${ }^{*}$ University Duisburg-Essen, Mercator School of Management, Lotharstraße 65, D-47057 Duisburg, Germany. email: Thorsten.Upmann@uni-duisburg-essen.de

${ }^{\dagger}$ Erasmus School of Economics, Erasmus University Rotterdam \& Tinbergen Institute, PO Box 1738, 3000 DR Rotterdam, The Netherlands. email: JMuller@ese.eur.nl
} 


\section{Introduction}

Merger activity between labour unions ${ }^{1}$ has a long history in Western industrialised countries and still continues to be a prevailing issue. Large numbers of mergers during the 20th century are documented by, for example, Chaison (1980) for the US, Griffin and Scarcebrook (1989) and Campling and Michelson (1997) for Australia, and by Buchanan $(1974,1981)$ and Waddington (1992) for the UK. For some countries this trend has even accelerated at the end of the century, which is shown, for example, by Campling and Michelson (1997) for Australia. Similarly, a vivid merger process of European trade unions at about the end of the last decade of the 20th century is documented by Willman (1996) and Ebbinghaus (2003); and expositions of most recent trade union mergers are given by Waddington (2006) for the EU, and by Moody (2009) for the US.

The nature of the forces and the processes that lead to union mergers are varying and depend on the particular institutional context. ${ }^{2}$ Yet, irrespective of the underlying reasons and forces that led to, and the institutional framework that allowed for the realisation of a particular merger, the concerned unions apparently spent a lot of money and effort in order to materialize a merger: Manifold obstacles must be surmounted and sometimes substantial opposition must be overcome before a new labour union could come into existence. In view of this effort spent in order to create large and presumably powerful (encompassing) labour unions, it is astonishing that an opposite trend could be observed during the last few years: "Small" professional unions (craft unions), which formerly had tariff unions together with larger industry unions, fought for their right to negotiate independently with employers. Notable separations occurred, for example, in Germany and South Korea, where since these split-ups employers are faced with the presence of multiple trade unions within one firm. While in Germany separations evolved without legislative changes, ${ }^{3}$ the frequent establishment of multiple labour unions within Korean companies emanated from a legislative change in 2011. ${ }^{4}$ Apparently, in these cases the separating employees do

${ }^{1}$ The notion union merger is used very broadly and includes both consolidations and transfers of authority.

${ }^{2}$ Compare, for example, Morris (1986) and Campling and Michelson (1997).

${ }^{3}$ For example, in Germany the Vereinigung Cockpit (VC) which has become the recognised and established representative of the pilots in wage negotiations. Subsequently the physicians' association Marburger Bund negotiated for the first time for a separate wage agreement in 2006. And most recently, the engine drivers' association GDL (Gewerkschaft Deutscher Lokomotivführer) fought for almost 12 month with the Deutsche Bahn for a separate wage agreement.

${ }^{4}$ Following an amendment to the Labor Union and Labor Relations Adjustment Act, effective as of July 1, 2011, the establishment of multiple labour unions within a company became allowed. Subsequently, from July 1, 2011 to August 31, 2012, the Labor Relations Commission of Korea dealt with more than 600 cases relating to the establishment of multiple labour unions. 
not feel well backed by the representatives of the large industry union, and believe that they may negotiate for more than what they got in joint negotiations.

This raises the question which of the two strategies - building up joint, encompassing large labour unions, or the creation of small craft-specific unions consisting of a homogeneous membership — is actually in the labourers' (mutual) interest. Do the respective employees benefit from joint negotiations with the employer(s), or may some group of employees suffer from joint bargains relative to what they could have obtained in autonomous bargains? The documented recent tendency towards separate negotiations suggests that, at least, some groups of labourers have not benefited from joint negotiations, or believe that they can negotiate for more on a stand-alone basis. - In this paper we seek to shed some light onto this issue. To this end, we use a microeconomic bargaining approach with two types of labourers.

Our approach ties in, of course, with former studies on the effects of potential splits and mergers of trade unions. To our knowledge, Horn and Wolinsky (1988), Davidson (1988), Jun (1989) and Dowrick (1989, 1993) were the first to analyse the effects of co-operation between different trade unions on negotiated wages and employment. With the exception of Dowrick (1989), who makes use of co-operative game theory, these authors follow a non-cooperative approach by applying Rubinstein's alternating-offer game to model labour market negotiations and to investigate the resulting effects of trade-union centralisation. While Horn and Wolinsky (1988) and Dowrick (1993) elaborate the pattern of trade union formation for varying degrees of complementarity and substitutability between two types of labour, ${ }^{5}$ Davidson (1988) and Dowrick (1989) assume that production requires one type of homogeneous labour only. In other words, while Horn and Wolinsky (1988) investigate the bargained wage contracts for a single firm and thus labourers' implied incentives to constitute a firm-specific encompassing union (trade-union merger along professions), Davidson (1988) and Dowrick $(1989,1993)$ investigate the labourers' incentives to constitute an industry union acting on behalf of the labourers of all firms (trade-union merger along firms of the same industry). ${ }^{6}$ Explicitly taking into account a firm's competitors allows for both output market effects and alternative patterns of unionisation: the possibility of vertical centralisation of trade unions (i.e., joint negotiations on behalf of labourers of different firms). More recently, Gürtzgen (2003) extends the analysis

\footnotetext{
5un (1989) assumes that the firm's revenue depends only on the total employed labour (measured in efficiency units), implying that the two types of labour are perfect substitutes in production (in the sense that the isoquants are straight lines).

${ }^{6}$ Mergers between trade unions may take place either along firms (of the same industry) and industries or along professions. In the first case a merger implies a centralisation along the industry dimension; in the second case, along the dimension of profession. In the literature, the first mode of centralisations is frequently referred to as vertical centralisation; the second, as horizontal centralisation (cf., for example, Gürtzgen, 2003). Actual mergers frequently include both dimensions. For example, German trade unions merged along both industries and professions.
} 
of Dowrick (1993) to multiple firms and various types of labour. This is done, however, for the special case of a Leontieff technology, where there is no substitutability between different types of labour, thereby limiting the applicability of her results.

To summarize the findings of the literature: While trade union mergers along different firms are profitable for the (organised) workforce under rather general conditions, mergers along the professional dimension are so only if different types of labour are complementary in production. Roughly, trade union mergers are profitable whenever higher wage claims on behalf of one group of labourers trigger positive spillover effects on the demand for the other group. This condition is fulfilled when the two types of labour are substitutes within a firm or (strategic) substitutes across firms. In this way an encompassing union accomplishes to negotiate for higher wages when compared with single unions. In short: Substitutability makes a strong case in favour of joint negotiations.

The literature, though, basically takes the institutional framework as exogenously given, and explores the consequences of alternative bargaining structures, that is, the consequences of different degrees of (de)centralisation of labour market negotiations for wages, employment, profits and labourers' utility. However, more recently attempts have been made to endogenise the degree of labour market (de)centralisation or, more broadly, the formation of labour market institutions. Yang (1995) and most notably Petrakis and Vlassis (2004) pursue a game theoretic approach to endogenise this bargaining structure. With the labour market institutions emanating from the equilibrium of a coalitional game, Petrakis and Vlassis succeed to explain the emergence of alternative wage bargaining structures as a consequence of productivity asymmetries among firms. In this paper, we also contribute to an endogenisation of the bargaining structure: While Petrakis and Vlassis focus on vertical centralisation (centralisation along firms), we endogenise the bargaining structure along occupations or crafts (horizontal centralisation).

Beyond the issue of the degree of centralisation, there is the question of the appropriate bargaining agenda, and thus of the equilibrium concept of the labour market. Although each of the aforementioned contributions on trade union mergers focuses on some other aspect of the issue, they have a common feature: All authors (with the exception of Yang, 1995) consider equilibria on the labour demand curve. However, apart from the competitive equilibrium, allocations on the labour demand curve are not Pareto efficient. Thus, whilst the literature explores whether or not employees can do better by adjusting the organisational structure of trade unions, they ignore the possibility for Pareto improvements which may (simply) be realised by changing the agenda of negotiations with employers, namely by extending the scope of negotiations to wages and employment. Good arguments, positive and normative, can be made in favour of efficient labour market contracts. From a positive point of view, labour 
unions seldom have the power to dictate wages (monopolistic union), ${ }^{7}$ and labour unions and employers' associations frequently do not bargain over wages alone (rightto-manage approach), but negotiate for working conditions, working times, workforce, manning rules, job guarantees etc. as well. In these cases where the union and the firm bargain, either formally or implicitly, about both wages and employment, efficient bargains are more descriptive than a model where the parties stop negotiating short of an efficient outcome. ${ }^{8}$

Secondly, from a normative perspective, there is no reason why rational parties should relinquish any potential of mutual gains. As Pareto efficiency requires that bargaining covers all variables entering the parties utility functions, the union and the employer (generically) benefit if they extend the scope of their negotiations to wages and employment. Yet, once they discover that there is some scope for mutual benefits, we should expect them to exhaust this potential; and if they won't, we should advise them to do so. In fact, even if there were evidence that the bulk of labour market conflicts is settled on the labour demand curve, the normative argument still applies - and thus calls for a thorough inspection of (axiomatic) solution concepts in the context of labour market negotiations.

On grounds of these arguments, we complement the theoretical literature on union mergers by using formal concepts of co-operative game theory to model efficient solutions of the labour market conflict. ${ }^{9}$ In particular, we assume that the employers' federation (or the firm) and the respective labour union bargain about both the wage rate and the employment level, and eventually settle their conflict according to

\footnotetext{
${ }^{7}$ Horn and Wolinsky (1988), p. 485f, criticize those who (simply) assume that unions are setting wages unilaterally rather than participating in some process of bargaining with the firm. We fully agree with this critique.

${ }^{8}$ Given the variety of national and sectoral institutional differences, it is not surprising that the empirical evidence for whether labour market equilibria lie on the labour demand curve or on the Pareto curve (or somewhere in between) is mixed. From the perspective of a positive analysis, it is important that there is some empirical evidence for equilibria on the Pareto curve - and this is undoubtedly the case, as, for example, Brown and Ashenfelter (1986), Svejnar (1986), MaCurdy and Pencavel (1986), Pencavel and Holmlund (1988), Bean and Turnbull (1988), Christofides (1990), Skedinger (1992), Bughin (1993), Gavosto (1997) and Dimova (2006) demonstrate. A highly valuable recent survey of this literature is provided by Lawson (2011), and the reader is referred to this work for more details on the empirical evidence of various labour market models.

${ }^{9}$ Efficient Nash bargains have been established in labour market economics by McDonald and Solow (1981), Creedy and McDonald (1991) and others, and have subsequently been applied by, for example, Bayındır-Upmann and Raith (2003, 2005), Boeters (2004) and Gerber and Upmann (2006). It has well been recognized that different solution concepts may bring about diverging comparative static effects (compare, for example, Gerber and Upmann, 2006). It would thus not be surprising if the consequence of union mergers were to vary with the solution concept applied as well. Yet, it is beyond the scope of this paper to extend the analysis to a series of alternative solution concepts. This issue must thus remain open for future research.
} 
the (asymmetric) Nash bargaining solution. ${ }^{10}$ Presuming this mode of settlement of the labour market conflict, we scrutinize the conditions under which horizontal trade union mergers may be favourable or unfavourable for the involved parties. This paper thus illuminates the structural features under which horizontal mergers may be expected to occur or may be regarded as stable (with respect to group specific split offs). In this sense we proceed along the lines of Horn and Wolinsky (1988) and Dowrick (1993) who focuses on possible co-operation between different craft unions at the firm (or industry) level. While these authors find that an encompassing labour union tends to negotiate for lower wages (when compared with craft-specific unions), and is thus likely to be split up, if both types of labourers are complements, we find that this results comes about under more general assumptions - and is thus reinforced. More precisely, we find that, if parties negotiate on wages and employment and are thus capable of arriving at some (mutually) efficient outcome - captured here by the asymmetric Nash bargaining solution - the decentralisation result found in the literature can be generalised for some arbitrary concave production structures, and does neither require complementarity between various types of labour nor linearity of the production function. ${ }^{11}$ Rather a simultaneous determination of all four economic variables, the wage rates and the employment levels of both groups, brings about the instability of a joint labour union as a remarkably robust result. ${ }^{12}$ This result becomes most pronounced when the (utilitarian) joint union completely substitutes the utility of one group of labourers by the other, eventually achieving at a corner solution where one group is merely paid the competitive wage while the other receives a substantial mark-up.

Beyond the forces already explained, two additional "spillover effects" are discovered which are responsible for strengthening the de-centralisation result: Firstly,

\footnotetext{
${ }^{10}$ Within a framework of meta bargaining van Damme (1986) and subsequently Trockel (2000, 2002), among others, provide strong arguments in favour of the Nash bargaining solution by demonstrating its Nash implementability. Also, the literature provides a series of non-cooperative games supporting co-operative solutions, that is, strategic games the equilibrium allocations of which coincide with the respective co-operative solution; for the Nash bargaining solution, recent noncooperative foundations are provided, for example, by Miyagawa (2002); Laruelle and Valenciano (2008); Miyakawa (2008); Kultti and Vartiainen (2010); Britz et al. (2010). (Since Binmore, 1987 the attempt to support or implement axiomatic solutions of co-operative games by Nash equilibria of suitably specified non-cooperative games is referred to as the Nash Program.)

${ }^{11}$ More precisely, we do not assume either sign for the cross-derivative of the production function with respect to both types of labour; we only presume that some minimal amount of each type of labour is indispensable in production, but that, except for low employment levels, both types may be either substitutes of complements.

${ }^{12}$ The aforementioned literature frequently imposes severe constraints on some of the variables in order to reduce the dimension of the problem. For example, in Horn and Wolinsky (1988) and Jun (1989) firms decide on employment before wage rates are negotiated. In addition, Jun assumes that employees fix a wage differential before wage negotiations commence. We do not impose such constraints on either wages or employment levels, but let parties freely negotiate them.
} 
the bargaining power of the amalgamated trade union is arguably some weighted average of the power of its constituting unions, which makes the stronger of the two losing some of its vigour. Secondly, and more importantly, the joint labour union now accounts for the negative effect that a higher wage demand on behalf of one group increases the firm's cost and thus reduces the scope for favourable deals on behalf of the other group - an effect which is present irrespective of whether the two types of labour are complements or substitutes in production. This negative spillover effect, which may be interpreted as if the encompassing union is more management (or firm) oriented than a craft union, makes the union moderate its wage demands. Finally, within the framework of efficient bargains where parties negotiate over all relevant variables, there is more scope for these forces to become effective. As a consequence, within our framework of efficient bargains, the existence of craft-specific trade unions is arguably more robust than previously suggested in the literature - and in this way our analysis contributes to explaining the recently observed trend towards the formation of smaller professional unions.

\section{Outline}

In order to focus on the pure effects of labour-market negotiations between labour unions and an employers' federation, we abstract from non-labour factors of production and from any potential non-competitive behaviour on any but the labour market. We therefore consider a competitive firm producing a homogeneous output, by means of two types of labour, which for expository purpose we call high- and low-skilled labour, but which should be considered as labels only. In general, the interests of each group of workers may be represented by a corresponding group-specific, professional labour union. In this case the employers' federation (or the firm) has to negotiate about wages and employment with each labour union separately but simultaneously. As the alternative organisational scenario, we consider the case where both labourer groups unite and form an encompassing union acting on behalf of both groups' interest. Naturally, we should expect a unification to emerge only if it is beneficial for both groups; and similarly, we should expect a united labour union to break asunder if it is in the interest of, at least, one group to constitute a separate, independent labour union. We therefore contrast the outcome of the negotiations between the firm and the two separate labour unions with the bargaining outcome when both labour groups formed an encompassing union. In this way we are able to explore whether, and if so under which conditions, either group prefers a joint or a craft-specific labour union. Equivalently, this procedure highlights the incentives to either leave the joint labour union and to form a professional labour union, or to unite the two independent labour unions by constituting an encompassing trade union. To this end we commence our analysis with the case where each group of workers is represented by a specific professional labour union, and proceed with the analysis of a joint (or encompassing) 
union. We then explore the stability of the two alternative organisational structures by comparing the respective outcomes. ${ }^{13}$

We find that a merger of two independent labour unions gives at least one group of labourers less than it would have achieved had it negotiated separately; and this unfavourable effect may be dramatic: Although, we hold the institutional framework fixed (the same solution concept is used before and after the merger), and we treat the situation between the two groups basically symmetric, it may happen that the bargaining outcome achieved under joint negotiations leaves one group of workers with the competitive wage, a result which is clearly unsatisfactory for this group. Effectively, since the joint labour union may trade the wage rate of one group for that of the other, corner solutions may come about unless the hands of union's executives are tied to some form of symmetry in wage gains. Symmetry, though, is exactly the condition under which it arguably happens that both types of labourers suffer from establishing a joint union.

The driving forces behind this result are twofold. Firstly, since both groups of labourers aim at a higher wage and employment level, their interests are parallel and in this sense rival: Each group aims at higher wages and a higher employment level, which tends to jeopardize the achievement of the same target by the other group though, as any successful bargain by one group leaves less room for the other to manoeuvre for a higher wage bill. Since separate labour unions ignore these effects imposed on the other group of labourers, their behaviour is more "aggressive" than is the behaviour of an encompassing labour union. ${ }^{14}$ In negotiations with the employers, the latter can never credibly mimic the behaviour of two independent labour unions by claiming to ignore the "external effects" imposed on the other group, for their constitution demands for the maximisation of the aggregate utility of all of its members.

Secondly, since a craft-specific labour union has a simple one-dimensional objective function, it simply negotiates for a high wage rate and high employment level on behalf of its homogeneous membership. The bargaining outcome will thus obviously yield a wage share that exceeds its competitive level. The objective function of an encompassing labour union, though, may be interpreted as a genuinely multidimensional objective: an operationalised compromise between two objectives. As a result, a joint labour union may trade a higher welfare of one group for a lower welfare of the other. This process of substitution may eventually leave one group with

\footnotetext{
${ }^{13}$ Our model can be thought of as a two-stage game: In the first stage, both groups of labourers decide on whether to constitute a joint union or two separate unions; in the second stage, both groups either bargain with the firm jointly or separately corresponding to the constitutional decisions of the first stage.

${ }^{14}$ This finding is fully in line with Horn and Wolinsky (1988), who also observe: when there are two independent unions their behaviour is more aggressive, since each union disregards the agreement reached by the other and bargains afresh for a share in the surplus.
} 
its reservation utility, the competitive outcome, while the other achieves at a very favourable outcome. Consequently, if the interests of both groups are parallel and the rationales for a merger thus coincide, a merger may turn out to be particularly problematic, a finding which is also consistent with the empirical literature:

The data [...] could possibly indicate that, where the unions planning to merge share the same underlying motivations, the merger process is more likely to be problematic than cases of merger where the rational is quite different for each of the unions involved. (Campling and Michelson, 1997, p. 240.)

\section{The Model}

The group of workers of type $i,(i=H, L)$, consists of a total mass of $N_{i}$ labourer households, all of which are assumed to have identical preferences. ${ }^{15}$ Each household is either employed at the full regular working time or has no job at all. An employed household of type $i$, receives a wage income equal to the (real) wage $w_{i}$. Postulating that a household's income is commensurate with utility, $w_{i}$ coincides with the utility level of type $i$ from labour income. An unemployed household, though, attains some fixed utility from the consumption of leisure and unemployment benefits, the sum of which, expressed in terms of an income equivalent, amounts to $\bar{w}_{i} \geq 0$, which can be interpreted as the reservation wage below which no household of type $i$ is willing to work. This implies that labour supply of group $i$ equals zero for all $w<\bar{w}_{i}$, equals $N_{i}$ for all $w>\bar{w}_{i}$, and is indeterminate, i.e., it is set-valued and equal to $\left[0, N_{i}\right]$ for $w=\bar{w}_{i}$.

The interests of all workers are represented by either two craft-specific labour unions or by one joint labour union, depending on the mode of organisation of the work force. We shall henceforth explore the consequences of both organisational structures, and contrast them with each other. In any case, each labour union is assumed to act on behalf on its members' interest, maximizing the sum of its members' utilities.

On the other side of the labour market there is a firm producing its output by means of both types of labour. Assuming that all other factors of production are fixed, these two types of labour are the only variable factors, so that output amounts to $Y=f(H, L)$, where $H$ and $L$ denote the employment levels of the respective type of labour. We assume that the production function $f$ is twice continuously differentiable, with both types of labour possessing positive, $f_{H}, f_{L}>0$, but decreasing marginal products, $f_{H H}, f_{L L}<0$. (Subindices of $f$ denote partial derivatives.) Moreover, let each type of labour be indispensable to sustain production, i. e., $f(0, L)=f(H, 0)=$

\footnotetext{
${ }^{15}$ For ease of presentation we will speak of $N_{H}\left(N_{L}\right)$ labourer households in the following.
} 
$0, \forall H, L,{ }^{16}$ and assume that $f\left(N_{H}, N_{L}\right)<N_{H} \bar{w}_{H}+N_{L} \bar{w}_{L}$, that is, not all workers can be employed at non-negative profits.

The interests of all firms are represented by an employers' federation seeking to maximize aggregate profits. Normalizing the price of the output good to unity, aggregate profits equal

$$
\Pi\left(w_{H}, w_{L}, H, L\right):=f(H, L)-w_{H} H-w_{L} L,
$$

where $w_{H}$ and $w_{L}$ denote the wages of the workers or type $H$ and $L$, respectively. Subsequently, we interpret profits as the income of some fixed factor of production, say capital. Differentiating the employers' objective function (profits) with respect to $w_{i}$ and $L_{i}, i=H, L$ (with $L_{H} \equiv H$ and $L_{L} \equiv L$ ), holding the level of $\Pi$ constant at, say, $\pi$, reveals that their indifference curves (iso-profit curves) are increasing in $L_{i}$ until $f_{i}=w_{i}$, and decreasing afterwards:

$$
\left.\frac{d w_{i}}{d L_{i}}\right|_{\Pi=\pi}=\frac{f_{i}-w_{i}}{L_{i}}
$$

To interpret this, note that $w_{i}=f_{i}(H, L), i=H, L$, characterizes the (inverse) labour-demand curve for type $i$-labour, given the employment level of the other type.

\section{Bargaining with two independent labour unions}

In case of separate bargains, where each group of labourers has formed its own union, the labour union of type $i$ labourer households, maximizes the aggregate utility of these $N_{i}$ households; or, in a framework of uncertainty, it maximizes the representative members' expected utility:

$$
\Psi_{i}\left(w_{i}, L_{i}\right):=L_{i} w_{i}+\left(N_{i}-L_{i}\right) \bar{w}_{i}, \quad i=H, L
$$

where $L_{i}$ denotes the mass of workers of type $i$ who obtain a job. ${ }^{17}$ Differentiation of the union's utility with respect to $w_{i}$ and $L_{i}$, holding the level of $\Psi_{i}$ constant at, say $\psi_{i}$, shows that the union's indifference curves are downward sloping whenever $w_{i}$ is above the reservation wage $\bar{w}_{i}$ :

$$
\left.\frac{d w_{i}}{d L_{i}}\right|_{\Psi_{i}=\psi_{i}}=-\frac{w_{i}-\bar{w}_{i}}{L_{i}}<0 .
$$

Gerber and Upmann (2006) have shown that in such a setting the negotiations between the firm/employers' association and a labour union constitute a bargaining

\footnotetext{
${ }^{16}$ Think of pilots and flight attendants or air traffic controllers and mechanics, for example: If either group is at strike, airplanes must stay on ground.

Note that our assumption $f(0, L)=f(H, 0)=0, \forall H, L$ together with $f(H, L)>0, \forall H, L>0$ implies $f_{H L}>0$ for a region sufficiently close to zero, (i.e., for low levels of employment both types are complements in the usual sense), but does not require $f_{H L}>0$ over the whole domain, unless we require $f$ to be linearly homogeneous.

${ }^{17}$ In accordance with our previous terminology we will speak of $L_{i}$ as the number of employed workers.
} 
problem in the sense of formal bargaining theory. For this reason we omit a corresponding proof and the translatation of our economic problem into the utility space, but study the bargaining problem in the wage-employment space directly.

We assume that both the wage rate and the employment level are determined by negotiations between the respective labour union and an employers' federation in an efficient way. That is, once an agreement is reached there is no room for renegotiations such that both parties can be made better off. ${ }^{18}$ In addition, we assume that in the case of craft-specific labour unions, negotiations between each labour union and the employers' federation take place simultaneously. Accordingly the two bargaining games are interdependent in the sense that the bargaining set of either game depends on the outcome of the other game. Thus, while there is bargaining and thus co-operative behaviour between each union and the firm, there is a kind of competition between the two unions, as each of them, when bargaining with the firm, takes the outcome of the negotiations of the rival union with the firm as given. ${ }^{19}$ Due to this simultaneity of negotiations the equilibrium outcome of the two bargaining games must satisfy a fixed point property: The solutions of the two games must be consistent in the sense that they mutually define bargaining games such that when solved (by application of the proposed solution concept), exactly these solutions materialise. ${ }^{20}$

Focusing on the (asymmetric) Nash bargaining solution, the outcome of the negotiations between the firm/employers' association and the labour union of type $i$ labourers may be found as the point of intersection of the Nash curve with the Pareto curve. $^{21}$ Both curves can be derived as the solution of the following maximisation problem:

$$
\begin{aligned}
\max _{w_{i}, L_{i}} & {\left[\Psi_{i}\left(w_{i}, L_{i}\right)-N_{i} \bar{w}_{i}\right]^{\mu_{i}}\left[\Pi\left(w_{H}, w_{L}, H, L\right)\right]^{1-\mu_{i}} } \\
= & {\left[L_{i}\left(w_{i}-\bar{w}_{i}\right)\right]^{\mu_{i}}\left[f(H, L)-w_{H} H-w_{L} L\right]^{1-\mu_{i}} . }
\end{aligned}
$$

\footnotetext{
${ }^{18}$ Gerber and Upmann (2006) provide a couple of arguments in favour of efficient bargains. Although arguments may be found why negotiations may stop short of an efficient outcome, for example, imperfect information and uncertainty, we shall follow their arguments here and assume efficient bargains.

${ }^{19}$ In a related, though more general framework Duggan (2001) uses the parallelity of co-operative behaviour within groups and competition between groups to define an equilibrium concept to which he refers as group Nash equilibrium.

${ }^{20}$ More formally, let $B_{1}=\left(S_{1}, d_{1}\right)$ and $B_{2}=\left(S_{2}, d_{2}\right)$ denote two bargaining games, and let $x_{i}=\phi\left(B_{i}\right)$ be a solution of $B_{i}$. Since the bargaining games are interdependent we have $B_{1}\left(x_{2}\right)=$ $\left(S_{1}\left(x_{2}\right), d_{1}\left(x_{2}\right)\right)$ and $B_{2}\left(x_{1}\right)=\left(S_{2}\left(x_{1}\right), d_{2}\left(x_{1}\right)\right)$. Then, an equilibrium requires $x_{1}=\phi\left(B_{1}\left(x_{2}\right)\right)$ and $x_{2}=\phi\left(B_{2}\left(x_{1}\right)\right)$, or more compactly in vectorial notation $x=\psi(x)$ with $\psi:=\phi \circ B$.

${ }^{21}$ When both groups of labourers are represented by independent labour unions, an internalisation (on the side of workers) fails to materialise, and in this sense Pareto efficiency of a bargaining outcome should be understood as internal (or bilateral) Pareto efficiency.
} 
where $\mu_{i} \in[0,1]$ and $1-\mu_{i}$ represent the bargaining power of the labour union of group $i, i=H, L$, and the employers' federation, respectively. ${ }^{22}$ In this formulation, we assumed that the disagreement (dispute or break-off) point equals the utility pair $\left(N_{i} \bar{w}_{i}, 0\right)$. This is consistent with our assumption $f(0, L)=f(H, 0)=0, \forall H, L$ (see p. 9, and in particular fn. 16), if we allow for strikes and lockouts. For if one group is at strike, and production thus breaks down, firms may at not cost suspend workers not being on strike, and need thus not pay their wages. $^{23}$

For either of both bargaining problems, the associated maximisation problem yields two first-order conditions: the Pareto curve and the Nash curve. The former is defined as the set of all employment-wage combinations such that both parties' indifference curves are tangent to each other, while the latter determines the bargained wage as the weighted average of the marginal and average productivity of labour, net of the cost of other factors. Defining the elasticity of excess utility of group $i(i=H, L)$ from a given wage rate by $\sigma_{i}(w):=w /\left(w-\bar{w}_{i}\right)$, we may write the Pareto curves as

$$
\begin{gathered}
\sigma_{H}\left(w_{H}\right)=\frac{w_{H}}{w_{H}-f_{H}(H, L)}, \\
\sigma_{L}\left(w_{L}\right)=\frac{w_{L}}{w_{L}-f_{L}(H, L)},
\end{gathered}
$$

while the Nash curves read $\operatorname{as}^{24}$

$$
\begin{aligned}
& w_{H}=\mu_{H} \frac{f(H, L)-w_{L} L}{H}+\left(1-\mu_{H}\right) f_{H}(H, L), \\
& w_{L}=\mu_{L} \frac{f(H, L)-w_{H} H}{L}+\left(1-\mu_{L}\right) f_{L}(H, L) .
\end{aligned}
$$

Taken together, equations (1) to (4) yield a system of four equations, the solution of which gives the negotiated wages $\hat{w}_{H}$ and $\hat{w}_{L}$ and the negotiated employment levels $\hat{H}$ and $\hat{L}$ - and correspondingly the equilibrium payoffs of the three parties: $\Psi_{H}\left(\hat{w}_{H}, \hat{H}\right), \Psi_{L}\left(\hat{w}_{L}, \hat{L}\right), \Pi\left(\hat{w}_{H}, \hat{w}_{L}, \hat{H}, \hat{L}\right)$. Apparently, equations (1) and (2) boil down to $\bar{w}_{H}=f_{H}(\hat{H}, \hat{L})$ and $\bar{w}_{L}=f_{L}(\hat{H}, \hat{L})$, respectively, implying that both types of labour are employed at the level where its marginal product equals its social cost - and thus both types of labour are employed at their socially efficient, that is, at their competitive levels (subsequently denoted by superscript $c$ ): $\hat{H}=H^{c}$ and $\hat{L}=L^{c}$, and therefore $\hat{Y}=Y^{c}:=f\left(H^{c}, L^{c}\right)$.

\footnotetext{
${ }^{22}$ As thoroughly explained by Binmore et al. (1986) the "bargaining power" of a party should reflect either asymmetries in the bargaining procedure (within a time preference model) or in the parties' beliefs (within a risk of breakdown model).

${ }^{23}$ If lockouts are not possible, firms profits may become negative during dispute; if, on the other hand, striking workers may be partially substituted by other workers, profits during dispute may become positive. There is, thus, some unavoidable degree of arbitrariness with respect to the disagreement payoffs.

${ }^{24}$ It is straightforward to verify that the Pareto curve is vertical and the Nash curve is decreasing in the $\left(H, w_{H}\right)$-space, respectively in the $\left(L, w_{L}\right)$-space.
} 
It therefore remains to determine the equilibrium wage rates. In view of eq. (3) respectively (4) we see that a higher (relative) bargaining power of the labour union of group $i$ brings about both a higher wage rate (at a constant employment level). In the limiting cases we find that for $\mu_{i} \rightarrow 0$, the wage rate converges to the competitive wage, $i . e ., \hat{w}_{i}=w_{i}^{c}=\bar{w}_{i}=f_{i}\left(H^{c}, L^{c}\right)$, while for $\mu_{i} \rightarrow 1$ workers acquire the total surplus and firms are thus left with zero profits: $\hat{w}_{i}=\left(\hat{Y}-\hat{w}_{-i} \hat{L}_{-i}\right) / \hat{L}_{i}$, implying $\Pi\left(\hat{w}_{H}, \hat{w}_{L}, \hat{H}, \hat{L}\right)=\hat{Y}-\hat{w}_{H} \hat{H}-\hat{w}_{L} \hat{L}=0$. For this reason, at most one union may exert monopoly power, and we thus henceforth assume $\mu_{H} \mu_{L}<1$.

In order to arrive at a closer look at the negotiated wage rates, it is helpful to solve eqs (3) and (4), evaluated at $\hat{w}_{H}, \hat{w}_{L}, \hat{H}, \hat{L}$, for both wage rates, yielding

$$
\begin{aligned}
\hat{w}_{H} & =\hat{\eta}_{H} \frac{\hat{Y}-f_{L} \hat{L}}{\hat{H}}+\left(1-\hat{\eta}_{H}\right) f_{H}, \\
\hat{w}_{L} & =\hat{\eta}_{L} \frac{\hat{Y}-f_{H} \hat{H}}{\hat{L}}+\left(1-\hat{\eta}_{L}\right) f_{L},
\end{aligned}
$$

where

$$
\hat{\eta}_{H}:=\frac{\mu_{H}\left(1-\mu_{L}\right)}{1-\mu_{H} \mu_{L}} \quad \text { and } \quad \hat{\eta}_{L}:=\frac{\mu_{L}\left(1-\mu_{H}\right)}{1-\mu_{H} \mu_{L}},
$$

with $\hat{\eta}_{H}, \hat{\eta}_{H} \in[0,1]$ and $\mu_{H} \mu_{L}<1$. Apparently, the negotiated wage rate of group $i$ is a weighted average of its marginal product, $f_{i}$, and the profit per worker (before labour cost) if the other factor were paid its marginal product, $\left(\hat{Y}-f_{-i} \hat{L}_{-i}\right) / \hat{L}_{i}$. This shows that workers of group $i$ bargain with the firm over the total available surplus (or economic rent), which equals the value of production net of social cost of labour. Alternatively, using $w_{H}^{c}=\bar{w}_{H}=f_{H}(\hat{H}, \hat{L})$ and $w_{L}^{c}=\bar{w}_{L}=f_{L}(\hat{H}, \hat{L})$ together with $\hat{H}=H^{c}$ and $\hat{L}=L^{c}$ and collecting terms, wage equations (5) and (6) may equivalently be expressed as

$$
\hat{w}_{H}=\hat{\eta}_{H} \frac{\pi^{c}}{\hat{H}}+\bar{w}_{H} \quad \text { and } \quad \hat{w}_{L}=\hat{\eta}_{L} \frac{\pi^{c}}{\hat{L}}+\bar{w}_{L},
$$

where $\pi^{c}:=\Pi\left(w_{H}^{c}, w_{L}^{c}, H^{c}, L^{c}\right)=f\left(H^{c}, L^{c}\right)-w_{H}^{c} H^{c}-w_{L}^{c} L^{c}$ denotes the profit achieved in a competitive labour market. Apparently, the wage rates bring about a mark-up on the respective reservation wage. Since the reservation wage coincides with the competitive wage rate, each employed worker is better off under union-firm bargains, when compared with the competitive outcome. Since the negotiated employment level equals the competitive level, $\hat{H}=H^{c}$ and $\hat{L}=L^{c}$, the wage share ${ }^{25}$ of group $i$, given by $\hat{\omega}_{i}:=\hat{w}_{i} \hat{L}_{i} / \hat{Y}$, exceeds the competitive wage share, defined as $\hat{\omega}_{i}^{c}:=\frac{\hat{L}_{i} f_{i}}{\hat{Y}}$. This can be seen very clearly by multiplying the wage equations by $\hat{L}_{i} / \hat{Y}$ and rearranging terms, arriving at

$$
\begin{aligned}
& \hat{\omega}_{H}=\hat{\omega}_{H}^{c}+\hat{\eta}_{H} \hat{\omega}_{K}^{c}, \\
& \hat{\omega}_{L}=\hat{\omega}_{L}^{c}+\hat{\eta}_{L} \hat{\omega}_{K}^{c},
\end{aligned}
$$

\footnotetext{
${ }^{25}$ The wage share is generally defined as $\omega_{i}:=w_{i} L_{i} / Y$.
} 
where $\hat{\omega}_{K}^{c}:=\frac{\hat{Y}-\hat{L} f_{L}-\hat{H} f_{H}}{\hat{Y}}$, denotes the income share of the fixed factor if all factors were paid their marginal products, to which we refer henceforth as competitive profit share. Consequently the profit share (or the share that accrues to the fixed factor, i. e., capital), defined as $\hat{\omega}_{K}:=1-\hat{\omega}_{H}-\hat{\omega}_{L}$ then amounts to ${ }^{26}$

$$
\hat{\omega}_{K}=\frac{\left(1-\mu_{H}\right)\left(1-\mu_{L}\right)}{1-\mu_{H} \mu_{L}} \hat{\omega}_{K}^{c}=\left(1-\hat{\eta}_{H}-\hat{\eta}_{L}\right) \hat{\omega}_{K}^{c}
$$

The negotiated wage share of group $i, \hat{\omega}_{i}$, thus equals the competitive wage share $\hat{\omega}_{i}^{c}$ plus some fraction $\hat{\eta}_{i}$ of the share of the competitive profit share. We thus see that the parties bargain over the distribution of the potential profit defined by competitive markets factor income. Since either group of labourers accomplishes to acquire a share that exceeds the respective competitive level, the profit share $\hat{\omega}_{K}$ necessarily falls short of its competitive level, i.e., $\hat{\omega}_{K} \leq \hat{\omega}_{K}^{c}$. Moreover, as equation (9) reveals, the profit share $\hat{\omega}_{K}$ is decreasing in the bargaining power of either group of labourers, $\mu_{H}$ and $\mu_{L}$. Accordingly, if the bargaining power of either labour union converges to unity, the respective union accomplishes to reap the full disposable profit, leaving firm owners and the other union with zero income (in excess of their reservation levels). ${ }^{27}$ In contrast, when the bargaining power of a labour union converges to zero, it fails to acquire any benefit in excess of the competitive level.

This result can also be illustrated by inspecting the ratio of the gains which the two types of labourers acquire from negotiations, more precisely, the ratio of excess wage payments received by both groups, generally defined as $R:=\frac{L\left(w_{L}-\bar{w}_{L}\right)}{H\left(w_{H}-\bar{w}_{H}\right)}$. Subsequently, let $\hat{R}:=\frac{\hat{L}\left(\hat{w}_{L}-\bar{w}_{L}\right)}{\hat{H}\left(\hat{w}_{H}-\bar{w}_{H}\right)}$ denote the ratio of excess wage payments under separate bargains. Although, $\hat{R}$ is by definition an endogenous variable, as it depends on the bargaining outcome $\left(\hat{w}_{H}, \hat{w}_{L}, \hat{H}, \hat{L}\right)$, it in fact turns out to be a constant, depending on the parameters $\mu_{H}$ and $\mu_{L}$ only.

Lemma 1. Under separate bargains, the ratio of excess excess wage payments is a constant, amounting to

$$
\hat{R}=\frac{\hat{\eta}_{L}}{\hat{\eta}_{H}}=\frac{\left(1-\mu_{H}\right) \mu_{L}}{\left(1-\mu_{L}\right) \mu_{H}}
$$

Proof: Expanding $\hat{R}$ and expressing the numerator and the denominator in terms of wage shares yields $\hat{R}=\left(\hat{\omega}_{L}-\hat{\omega}_{L}^{c}\right) /\left(\hat{\omega}_{H}-\omega_{H}^{c}\right)$. Substituting from eqs (7) and (8) provides the first equality; and then using the definitions of $\hat{\eta}_{H}$ and $\hat{\eta}_{L}$, the second.

\footnotetext{
${ }^{26}$ Note that $\frac{\left(1-\mu_{H}\right)\left(1-\mu_{L}\right)}{1-\mu_{H} \mu_{L}} \in[0,1]$.

${ }^{27}$ In the four polar cases where either of both labour unions has either no or full bargaining power, we obtain

$$
\begin{array}{ll}
\left.\hat{\eta}_{H}\right|_{\mu_{H}=0}=0, & \left.\hat{\eta}_{L}\right|_{\mu_{H}=0}=\mu_{L},\left.\quad \Rightarrow \quad \hat{\eta}_{K}\right|_{\mu_{H}=0}=1-\mu_{L}, \\
\left.\hat{\eta}_{H}\right|_{\mu_{H}=1}=1, & \left.\hat{\eta}_{L}\right|_{\mu_{H}=1}=0,\left.\quad \Rightarrow \quad \hat{\eta}_{K}\right|_{\mu_{H}=1}=0 .
\end{array}
$$
}

and correspondingly if $\mu_{L}$ equals either 0 or 1 . 
According to Lemma 1 the ratio of wage payments received by both parties, in excess of their respective reservation wages, is uniquely determined by the parameters of bargaining power of the two labour unions. This ratio is positively affected by $\mu_{L}$ and negatively by $\mu_{H}$, implying that the higher the bargaining power of each craftunion, the higher total net wage payments received by the respective group relative to those of the other. (Note that for the symmetric case we have $\mu_{H}=\mu_{L} \Leftrightarrow \hat{R}=1$.) Moreover, observe that, by definition, $R$ also coincides with the ratio of excess wage shares. (We have already made use of this in the proof of Lemma 1.) Consequently, not only does a higher bargaining power of group $i$ increase its wage share $\hat{\omega}_{i}$ and thus its gain over the competitive wage share $\hat{\omega}_{i}-\hat{\omega}_{i}^{c}$, but also does group $i$ achieve more in relative terms.

\section{Bargains with a united labour union}

We now consider the alternative organisational structure of the labour force where both groups of labourers have formed a joint labour union which acts on behalf of all labourers' interests. In accordance with our previous specification of the objective functions of the two separate unions, we assume that the utility of this joint union is the sum of the utilities of its constituents: ${ }^{28}$

$$
\Psi\left(w_{H}, w_{L}, H, L\right):=H w_{H}+\left(N_{H}-H\right) \bar{w}_{H}+L w_{L}+\left(N_{L}-L\right) \bar{w}_{L} .
$$

In negotiations with the employers' federation, the parties bargain about $w_{H}, w_{L}$, $H$ and $L$ simultaneously. The bargaining outcome is thus obtained as the solution of the maximisation problem:

$$
\begin{aligned}
\max _{w_{H}, w_{L}, H, L} & {\left[\Psi\left(w_{H}, w_{L}, H, L\right)-N_{H} \bar{w}_{H}-N_{L} \bar{w}_{L}\right]^{\mu}[\Pi(w, L)]^{1-\mu} } \\
= & {\left[H\left(w_{H}-\bar{w}_{H}\right)+L\left(w_{L}-\bar{w}_{L}\right)\right]^{\mu}\left[f(H, L)-w_{H} H-w_{L} L\right]^{1-\mu}, }
\end{aligned}
$$

where $\mu$ is some weighted average of the bargaining power of both groups of labourers. $^{29}$ More precisely, $\mu$ is a short hand notation for some function $\mu:[0,1] \times[0,1] \rightarrow$ $[0,1]$ which is weakly increasing in both arguments, with $\mu\left(\mu_{H}, \mu_{L}\right) \in\left[\min \left\{\mu_{H}, \mu_{L}\right\}\right.$, $\left.\max \left\{\mu_{H}, \mu_{L}\right\}\right], \forall \mu_{H}, \mu_{L} \in[0,1]$.

\footnotetext{
${ }^{28}$ This assumption is also standard in the literature, compare, for example, Davidson (1988) and Dowrick (1989, 1993).

${ }^{29}$ The bargaining power of the joint labour union may, for example, be equal to the arithmetic, the harmonic or the geometric mean of $\mu_{H}$ and $\mu_{L}$, but it may also be equal to either $\min \left\{\mu_{H}, \mu_{L}\right\}$ or $\max \left\{\mu_{H}, \mu_{L}\right\}$. The way $\mu$ is composed of $\mu_{H}$ and $\mu_{L}$ should reflect the actual mode of the unification of the two labour unions. However, the reasons and the procedure of such a unification are multifarious, and equally broad may be the resulting range of the bargaining power of a unified labour union. Accordingly, a theory of trade union formation tailored to the particular circumstances of the unification under consideration, is necessary to explain, and thus to endogenise, the resulting value of $\mu$. - But such an endogenisation, though desirable, is beyond the scope of this paper.
} 
The first-order conditions of this maximisation problem are given by

$$
\begin{aligned}
\sigma_{H}\left(w_{H}^{*}\right) & =\frac{w_{H}^{*}}{w_{H}^{*}-f_{H}\left(H^{*}, L^{*}\right)}, \\
\sigma_{L}\left(w_{L}^{*}\right) & =\frac{w_{L}^{*}}{w_{L}^{*}-f_{L}\left(H^{*}, L^{*}\right)}, \\
w_{H}^{*} & =\mu_{H}^{*} \frac{f\left(H^{*}, L^{*}\right)-w_{L}^{*} L^{*}}{H^{*}}+\left(1-\mu_{H}^{*}\right) f_{H}\left(H^{*}, L^{*}\right), \\
w_{L}^{*} & =\mu_{L}^{*} \frac{f\left(H^{*}, L^{*}\right)-w_{H}^{*} H^{*}}{L^{*}}+\left(1-\mu_{L}^{*}\right) f_{L}\left(H^{*}, L^{*}\right),
\end{aligned}
$$

where

$$
\mu_{H}^{*}:=\frac{\mu}{1+(1-\mu) R^{*}}, \quad \mu_{L}^{*}:=\frac{\mu}{1+(1-\mu) R^{*-1}}, \quad \text { and } \quad R^{*}:=\frac{L^{*}\left(w_{L}^{*}-\bar{w}_{L}\right)}{H^{*}\left(w_{H}^{*}-\bar{w}_{H}\right)} .
$$

Again, the bargaining agreement is determined by the intersection of the respective Nash curve with the respective Pareto curve. Moreover, carefully observe that conditions (10)-(13) coincide with the corresponding conditions (1)-(4) for separate negotiations, except that in eqs (12) and (13) $\mu_{H}$ and $\mu_{L}$ have been replaced by $\mu_{H}^{*}$ and $\mu_{L}^{*}$, respectively — we subsequently refer to the latter as notional bargaining power. The replacement of $\mu_{H}$ and $\mu_{L}$ by $\mu_{H}^{*}$ and $\mu_{L}^{*}$, respectively, seems to be a subtle difference, but as we shall see this turns out to be crucial and represents the driving force behind our results.

Let us first investigate conditions (10) and (11). From these it follows that $\bar{w}_{H}=f_{H}\left(H^{*}, L^{*}\right)=: f_{H}^{*}$ and $\bar{w}_{L}=f_{L}\left(H^{*}, L^{*}\right)=: f_{L}^{*}$. Recalling that we also found in the case of independent labour unions $\bar{w}_{H}=f_{H}(\hat{H}, \hat{L})$ and $\bar{w}_{L}=f_{L}(\hat{H}, \hat{L})$, we conclude $\hat{H}=H^{*}=H^{c}$ and $\hat{L}=L^{*}=L^{c}$, and therefore $\hat{Y}:=f(\hat{H}, \hat{L})=Y^{c}:=$ $f\left(H^{c}, L^{c}\right)=Y^{*}:=f\left(H^{*}, L^{*}\right)$. So, as a first central result we obtain that both institutional scenarios lead to the same employment levels, which coincide with the respective competitive levels.

Proposition 1. Separate and joint negotiations both lead to the same employment levels, which in turn coincide with the competitive levels:

$$
\hat{H}=H^{*}=H^{c}, \quad \hat{L}=L^{*}=L^{c},
$$

and thus $\hat{Y}=Y^{*}=Y^{c}$.

Since employment and thus production levels are fixed and equal to their competitive levels under both bargaining regimes, the marginal products of labour must be so as well. Consequently the competitive wages shares, $\omega_{i}^{* c}:=\left(L_{i}^{*} f_{i}^{*}\right) / Y^{*}(i=H, L)$, and the competitive profit share, $\omega_{K}^{* c}:=\left(Y^{*}-L^{*} f_{L}^{*}-H^{*} f_{H}^{*}\right) / Y^{*}$ under joint negotiations, coincide with the respective shares under negotiations with independent labour unions, $\hat{\omega}_{i}^{c}$ and $\hat{\omega}_{K}^{c}$, for these shares do not depend on actual wages. 
Corollary 1. Separate and joint negotiation both lead to the same competitive wage shares, i. e., $\hat{\omega}_{H}^{c}=\omega_{H}^{* c}$ and $\hat{\omega}_{L}^{c}=\omega_{L}^{* c}$, and to the same competitive profit share, i.e., $\hat{\omega}_{K}^{c}=\omega_{K}^{* c}$.

According to Corollary 1, we may subsequently drop the scenario-specific symbols and safely write (whenever appropriate) $\omega_{i}^{c}:=\omega_{i}^{* c} \equiv \hat{\omega}_{i}^{c}$, for $i=H, L, K$ for the competitive wage and profit shares.

A direct consequence of Proposition 1 is that any difference in bargaining outcome of the two scenarios must originate from discrepancies in wage rates. So we shall next explore eqs (12) and (13) determining the wage rates for a joint labour union. To this end, it is instructive to solve these equations for the negotiated wage rates, yielding

$$
\begin{aligned}
& w_{H}^{*}=\eta_{H}^{*} \frac{Y^{*}-f_{L}^{*} L^{*}}{H^{*}}+\left(1-\eta_{H}^{*}\right) f_{H}^{*}, \\
& w_{L}^{*}=\eta_{L}^{*} \frac{Y^{*}-f_{H}^{*} H^{*}}{L^{*}}+\left(1-\eta_{L}^{*}\right) f_{L}^{*},
\end{aligned}
$$

where

$$
\eta_{H}^{*}:=\frac{\mu_{H}^{*}\left(1-\mu_{L}^{*}\right)}{1-\mu_{H}^{*} \mu_{L}^{*}}=\frac{\mu}{1+R^{*}} \quad \text { and } \quad \eta_{L}^{*}:=\frac{\mu_{L}^{*}\left(1-\mu_{H}^{*}\right)}{1-\mu_{H}^{*} \mu_{L}^{*}}=\frac{\mu}{1+R^{*-1}} .
$$

(The latter equalities result from substituting the definitions of $\mu_{H}^{*}$ and $\mu_{L}^{*}$.) Similar to negotiations with separate labour unions, the negotiated wage rate of group $i$ is a weighted average of its marginal product, $f_{i}^{*}$, and the profit per worker if the other factor were paid its marginal product, $\left(Y^{*}-f_{-i}^{*} L_{-i}^{*}\right) / L_{i}^{*}$. However, the weights attached to the two components differ, as $\hat{\eta}_{i}$ is replaced by $\eta_{i}^{*}$ under joint bargains.

Irrespective of whether we consider the implicit representation, given by eqs (12) and (13), or the explicit representation of the wage rates, given by eqs (14) and (15), we readily find that the (relative) weights attributed to the marginal and the average products of labour are modified, when compared with the weights under separate bargains. This modification consists of two components: Firstly, the (relative) bargaining power of the joint labour union is some weighted average of those of the two single unions, $\mu_{H}$ and $\mu_{L}$, which are now replaced by the bargaining power of the joint labour union $\mu$. This implies, ceteris paribus, that the post-unification bargaining power is (weakly) lower for the labour union with the higher pre-unification bargaining power, and (weakly) higher for the other one. Secondly, the fact that the joint labour union takes into account the utilities of both groups of employees results in the appearance of the additional terms $(1-\mu) R^{*}$ and $(1-\mu) R^{*-1}$ in the denominator of $\mu_{H}^{*}$ and $\mu_{L}^{*}$, respectively. ${ }^{30}$ Because these terms are both non-negative, we infer

$$
\mu \geq \mu_{H}^{*} \quad \text { and } \quad \mu \geq \mu_{L}^{*} . \quad\left[\text { and also } \mu \geq \eta_{H}^{*}, \mu \geq \eta_{L}^{*}\right. \text { ]. }
$$

\footnotetext{
${ }^{30}$ Note that since $R^{*}$ depends on the equilibrium values of $H, L, w_{H}$ and $w_{L}$, the notional bargaining powers $\mu_{H}^{*}$ and $\mu_{L}^{*}$ are endogenous as well. This dependence can best be seen by considering the equivalence $\mu_{H}^{*}>\mu_{L}^{*} \Leftrightarrow R^{*}<1 \Leftrightarrow H^{*}\left(w_{H}^{*}-\bar{w}_{H}\right)>L^{*}\left(w_{L}^{*}-\bar{w}_{L}\right)$. Thus, the notional bargaining power of the $H$-type labourers exceeds that of the $L$-type labourers if, and only if, the former groups attain a higher net utility than the latter.
} 
The notional bargaining power of each union can thus not be larger than the actual bargaining power of the joint labour union - and they are strictly smaller if $R^{*} \in$ $(0,+\infty)$. In other words, the notional bargaining power of the joint union is for each group of workers lower than the average bargaining power of the two autonomous labour unions, $\mu$.

Intuitively, $R^{*}$ accounts for the wage (and employment) effects which a labour contract on behalf of one type of labour exerts on the other. ${ }^{31}$ While a craft-specific labour union ignores these "externalities", an encompassing labour union acknowledges for these effects. Consequently, a joint labour union uses, the variables $w_{i}$ (and $\left.L_{i}\right)$ to affect the welfare of both types of workers, - and may thus trade $L$-type workers' welfare for $H$-type workers' welfare (and vice versa), as both are substitutes in its objective function. This "internalisation" is reflected in $R^{*}$ and is thus a component of the parameters of notional bargaining power, $\mu_{H}^{*}$ and $\mu_{L}^{*}$.

Equivalently expressing the bargaining outcome in terms of the wage shares we obtain

$$
\begin{aligned}
& \omega_{H}^{*}=\omega_{H}^{* c}+\eta_{H}^{*} \omega_{K}^{* c}, \\
& \omega_{L}^{*}=\omega_{L}^{* c}+\eta_{L}^{*} \omega_{K}^{* c},
\end{aligned}
$$

from which we infer that the profit share, $\omega_{K}^{*}:=1-\omega_{H}^{*}-\omega_{L}^{*}$, equals

$$
\omega_{K}^{*}=(1-\mu) \omega_{K}^{* c}
$$

As in the case of independent labour unions, the negotiated wage share equals the competitive wage share $\omega_{i}^{* c}$ plus some fraction $\eta_{i}^{*}$ of the share of the fixed factor, when all factors were paid their marginal products $\omega_{K}^{* c}$. Since $\eta_{i}^{*}$ is increasing in $\mu$, both the wage rate and the wage share (of group $i$ ) are, ceteris paribus, increasing in bargaining power of the joint union - while the profit share is decreasing in $\mu$.

Under joint bargains the ratio of excess (or net-) wage payments, $R^{*}$, is determined by the ratio of notional bargaining power of the two groups of labourers.

Lemma 2. Under joint bargains, the ratio of excess wage payments amounts to

$$
R^{*}=\frac{\eta_{L}^{*}}{\eta_{H}^{*}}=\frac{\left(1-\mu_{H}^{*}\right) \mu_{L}^{*}}{\left(1-\mu_{L}^{*}\right) \mu_{H}^{*}}
$$

Proof: Expanding $R^{*}$ and expressing the numerator and the denominator in terms of wage rates yields $R^{*}=\left(\omega_{L}^{*}-\omega_{L}^{* c}\right) /\left(\omega_{H}^{*}-\omega_{H}^{* c}\right)$. Substituting from eqs (16) and (17) provides the first equality; and then using the definitions of $\eta_{H}^{*}$ and $\eta_{L}^{*}$, the second.

\footnotetext{
${ }^{31}$ As Proposition 1 shows the employment effect disappears under the present specification.
} 


\section{Who benefits from a joint labour union?}

It is now natural to ask whether separate bargains are in the interest of either group of workers, or joint negotiations are favourable for both groups. This leads us to the question whether two separate unions or a joint union will materialise. Treating each union as a player with utility functions $U_{L}=\Psi_{L}$ and $U_{H}=\Psi_{H}$ as defined above, we may look at the problem of constituting a joint union from two alternative game theoretic perspectives: From a non-cooperative perspective we may view this problem of a normal form game with two players, $N=\{L, H\}$, where each player (union) $i \in N$ selects a strategy $s_{i}$ from the set $S=\{a, j\}$, with elements interpreted as choosing "stay alone" $(a)$ or "constitute joint union" $(j)$. A joint union is established if, and only if, both players choose to play $j$, otherwise two independent labour unions are established, and the resulting payoffs are given by

$$
\left(U_{L}, U_{H}\right)\left(s_{L}, s_{H}\right)= \begin{cases}\left(\Psi_{L}^{*}, \Psi_{H}^{*}\right) & \text { if }\left(s_{L}, s_{H}\right)=(j, j), \\ \left(\hat{\Psi}_{L}, \hat{\Psi}_{H}\right) & \text { else, }\end{cases}
$$

with $\hat{\Psi}_{i}$ and $\Psi_{i}^{*}$ as given in Sections 4 and 5 respectively. To solve this game, the applied equilibrium concept is that of a Nash equilibrium. - Alternatively, from the perspective of co-operative game theory we may view this problem as a coalitional game with non-transferable utility. With $N=\{L, H\}$, there is only one coalition, the grand coalition $N$, along with the singletons $\{L\}$ and $\{H\}$, with resulting sets of payoff allocations $V(N)=\operatorname{compH}\left(\left\{\Psi_{L}^{*}, \Psi_{H}^{*}\right\}\right)$ and $V(\{i\})=\operatorname{compH}\left(\left\{\hat{\Psi}_{i}\right\}\right), \forall i \in N$. (For some set $X, \operatorname{compH}(X)$ denotes its comprehensive hull.) ${ }^{32}$ To solve this game, we apply the concept of the core. ${ }^{33}$ Clearly, in our case the two approaches are equivalent in the sense that the formation of a joint union is in the core of the coalitional game if, and only if, a joint union is formed in the Nash equilibrium of the non-cooperative game. For this reason, we only need to check whether both groups of labourers benefit from a joint union or either of both may be better off by staying alone - and may leave the specific interpretation of game-theoretic foundation to the reader.

For a given group of labourers, an independent labour union is more favourable than the constitution of a joint labour union, if their aggregated utility is higher under separate negotiations when compared with joint negotiations. A nice consequence of

\footnotetext{
${ }^{32}$ In our framework, as in many other real world applications, the payoff allocations available to a coalition depend on the actions taken by other players. (For a thorough discussion of this issue see Ray, 2007.) To deal with this issue, we assume that subsequent to the coalitional game, the resulting bargaining games are solved according to the specified solution concept. In this sense, non-cooperative behaviour enters into the sequential (two stage) game, where unions first decide whether to constitute a joint union or to stay separate and then negotiate with the firm; and the applied solution concept of this game is subgame-perfectness.

${ }^{33}$ That is, the allocation $x$ is in the core if, and only if, it is feasible for the grand coalition, i. e. $x \in V(N)$, and no other coalition, which here means no single player, has a feasible vector which is strictly better for all of its members.
} 
the fixed employment levels (see Proposition 1) is that this comparison can conveniently be executed in terms of the resulting wage shares. Making use of Corollary 1, a direct comparison of eqs (7)-(9) with eqs (16)-(18) is readily accessible, as the wage shares and the profit share under separate and joint negotiations reduce to

$$
\begin{array}{lll}
\hat{\omega}_{H}=\omega_{H}^{c}+\hat{\eta}_{H} \omega_{K}^{c}, & \hat{\omega}_{L}=\omega_{L}^{c}+\hat{\eta}_{L} \omega_{K}^{c}, & \hat{\omega}_{K}=\left(1-\hat{\eta}_{H}-\hat{\eta}_{L}\right) \omega_{K}^{c}, \\
\omega_{H}^{*}=\omega_{H}^{c}+\eta_{H}^{*} \omega_{K}^{c}, & \omega_{L}^{*}=\omega_{L}^{c}+\eta_{L}^{*} \omega_{K}^{c}, & \omega_{K}^{*}=(1-\mu) \omega_{K}^{c} .
\end{array}
$$

The wage rate and thus the wage share formulae under separate and joint bargains differ only in the values of the "effective bargaining power": $\hat{\eta}_{i}$ vis-à-vis $\eta_{i}^{*}, \quad(i=$ $H, L)$. Note that in both scenarios the sum of the wage shares of both groups of labourers is constant, as $\hat{\omega}_{H}+\hat{\omega}_{L}=1-\left(\left(1-\mu_{H}\right)\left(1-\mu_{L}\right) /\left(1-\mu_{H} \mu_{L}\right)\right) \omega_{K}^{c}$ and $\omega_{H}^{*}+\omega_{L}^{*}=1-(1-\mu) \omega_{K}^{c}$. Apparently, the joint labour union bargains with the employers' federation over the pure economic rent (profit), $\pi^{c}$, or, equivalently, over the competitive profit share $\omega_{K}^{c}:=\pi^{c} / Y^{c}$. The higher the relative bargaining strength of the (joint) labour union the more labourers succeed to acquire a larger share of the pure economic rent.

Next we shall derive the central result of the paper: that at least one group of labourers benefits from leaving the joint union (if it is already in existence) and from constituting its own craft-specific labour union; or from a pre-unification point of view, that at least one group of labourers suffers from a unification of the two professional labour unions and from the formation of an encompassing union. In order to see this, we compare the respective wage shares with each other. In particular, comparing $\hat{\omega}_{H}$ with $\omega_{H}^{*}$ shows that bargaining with separate labour unions is beneficial for the labourers of type $H$ if, and only if,

$$
\hat{\omega}_{H}>\omega_{H}^{*} \quad \Leftrightarrow \quad \hat{\eta}_{H}>\eta_{H}^{*} \quad \Leftrightarrow \mu<\frac{\mu_{H}\left(1-\mu_{L}\right)}{1-\mu_{H} \mu_{L}}\left(1+R^{*}\right) .
$$

Correspondingly, we obtain for the wage share of the labourers of type $L$ :

$$
\hat{\omega}_{L}>\omega_{L}^{*} \quad \Leftrightarrow \quad \hat{\eta}_{L}>\eta_{L}^{*} \quad \Leftrightarrow \mu<\frac{\mu_{L}\left(1-\mu_{H}\right)}{1-\mu_{H} \mu_{L}} \frac{1+R^{*}}{R^{*}}
$$

Conditions (19) and (20) provide the crucial conditions indicating under which qualifications a particular group of labourers is better off under separate negotiations.

It is expedient to commence the analysis with an investigation of the profit shares under both scenarios. From eqs (9) and (18) we know

$$
\hat{\omega}_{K}=\frac{\left(1-\mu_{H}\right)\left(1-\mu_{L}\right)}{1-\mu_{H} \mu_{L}} \hat{\omega}_{K}^{c} \quad \text { and } \quad \omega_{K}^{*}=(1-\mu) \omega_{K}^{* c},
$$

respectively. Comparing $\hat{\omega}_{K}$ and $\omega_{K}^{*}$ we find: 
Proposition 2. The profit share under separate bargains (weakly) falls short of the profit share under joint bargains:

$$
\hat{\omega}_{K} \leq \omega_{K}^{*},
$$

and both inequalities hold strictly if either $\min \left\{\mu_{H}, \mu_{L}\right\}>0$ or $\max \left\{\mu_{H}, \mu_{L}\right\}>\mu$ (or both).

Proof: From Corollary 1 we know that $\hat{\omega}_{K}^{c}=\omega_{K}^{* c}$, so that

$$
\hat{\omega}_{K} \leq \omega_{K}^{*} \quad \Leftrightarrow \quad 1-\mu \geq \frac{\left(1-\mu_{H}\right)\left(1-\mu_{L}\right)}{1-\mu_{H} \mu_{L}}=: \phi\left(\mu_{H}, \mu_{L}\right) .
$$

Assume w. l.o.g. that $\mu_{H} \geq \mu_{L}$ and thus $\mu_{H} \geq \mu \geq \mu_{L}$. Since $\phi$ is decreasing in both of its arguments, the function $\phi\left(\mu_{H}, \cdot\right)$ is maximal (on $\left[0, \mu_{H}\right]$ ) for $\mu_{L}=0$ with $\phi\left(\mu_{H}, 0\right)=1-\mu_{H} \leq 1-\mu$. Consequently, the condition $1-\mu \geq \phi\left(\mu_{H}, \mu_{L}\right)$ is fulfilled and $\hat{\omega}_{K} \leq \omega_{K}^{*}$ thus holds for any pair $\left(\mu_{H}, \mu_{L}\right) \in[0,1] \times[0,1]$, with $\mu_{L} \leq \mu_{H}$. Finally, $\phi\left(\mu_{H}, \mu_{L}\right)<1-\mu$ for all $\left(\mu_{H}, \mu_{L}\right) \in(0,1] \times(0,1]$, and since $\phi\left(\mu_{H}, 0\right)=1-\mu_{H}=1-\mu$ if, and only if, $\mu_{H}=\mu$ (including the case $\mu_{H}=0=\mu$ ), the equality $\phi\left(\mu_{H}, \mu_{L}\right)=1-\mu$ holds if, and only if, $\mu_{L}=0$ and $\mu_{H}=\mu$.

According to Proposition 2 the profit share is higher under joint bargains than under separate bargains. Since we know from Proposition 1 that output is the same under both regimes, a higher profit share immediately translates into a higher profit level. We can thus conclude that the firm is worse off under separate bargains when compared with joint bargains.

Since the sum of the wages shares of both groups of labourers is one minus the profit share, it immediately follows that

$$
\hat{\omega}_{K} \leq \omega_{K}^{*} \Leftrightarrow 1-\hat{\omega}_{K} \geq 1-\omega_{K}^{*} \Leftrightarrow \hat{\omega}_{H}+\hat{\omega}_{L} \geq \omega_{H}^{*}+\omega_{L}^{*} .
$$

Since the sum of both wage shares is (weakly) lower under joint bargains, we conclude:

Proposition 3. For at least one group of labourers the wage share under joint bargains (weakly) falls short the wage share under separate bargains:

$$
\hat{\omega}_{H} \geq \omega_{H}^{*} \quad \text { or } \quad \hat{\omega}_{L} \geq \omega_{L}^{*},
$$

(or both). Both inequalities hold strictly if either $\min \left\{\mu_{H}, \mu_{L}\right\}>0$ or $\max \left\{\mu_{H}, \mu_{L}\right\}>$ $\mu$ (or both).

Finally, it remains to show that it may in fact happen that both groups of labourers are worse off under joint bargains. In order to see this, it suffices to provide a simple example. Assume that $\mu_{H}=\mu_{L}=\mu$. Then we have $\hat{\eta}_{H}=\hat{\eta}_{L}=\mu /(1+\mu)$ so that

$$
\begin{aligned}
\hat{\omega}_{H}>\omega_{H}^{*} \quad \Leftrightarrow \quad \hat{\eta}_{H}>\eta_{H}^{*} \quad \Leftrightarrow \frac{\mu}{1+\mu}>\frac{\mu}{1+R^{*}} \quad \Leftrightarrow \mu<R^{*}, \\
\hat{\omega}_{L}>\omega_{L}^{*} \quad \Leftrightarrow \quad \hat{\eta}_{L}>\eta_{L}^{*} \quad \Leftrightarrow \frac{\mu}{1+\mu}>\frac{\mu}{1+R^{*-1}} \quad \Leftrightarrow \quad \mu<\frac{1}{R^{*}} .
\end{aligned}
$$


Thus, a lower wage share materializes for both groups of labourers if $\mu$ is sufficiently low (or equivalently, if $R^{*}$ is sufficiently close to unity).

Corollary 2. Let $\mu_{H}=\mu_{L}$. Both groups of labourers are worse off under joint negotiations if, and only if, $\mu<\min \left\{R^{*}, 1 / R^{*}\right\}$.

Loosely speaking, the condition $\mu<\min \left\{R^{*}, 1 / R^{*}\right\}$ is fulfilled if the bargaining outcome reflects a sufficient degree of symmetry, in the sense that the ratio of excess wage incomes $R^{*}=\left(L^{*}\left(w_{L}^{*}-\bar{u}_{L}\right) /\left(H^{*}\left(w_{H}^{*}-\bar{u}_{H}\right)\right.\right.$ does not differ substantially from unity. In other words, as long as the excess utilities under joint bargaining are not "too different", a split of the joint union into two separate ones is beneficial for both labourer groups. - Thus, as this example, which merely presumes similar bargaining strength, shows, the outcome that both groups of labourers are worse off under joint negotiations is by no means pathological, it rather seems to be the rule than an exception.

Finally, we wish to emphasize that as the number of employed labourers is constant over both regimes (see Proposition 1), all of our results directly translate into corresponding statements regarding wage rates. Because each union member retains his/her employment status, a higher wage share must directly translate into a higher wage rate, so that employed union members are strictly better off (as they receive higher wages without losing their job), and unemployed members are unaffected (as their number stays constant). Thus, we immediately infer from Proposition 3 that a corresponding result must also hold for the wage rates.

Corollary 3. For at least one group of labourers the wage rate under joint bargains (weakly) falls short the wage rate under separate bargains:

$$
\hat{w}_{H} \geq w_{H}^{*} \quad \text { or } \quad \hat{w}_{L} \geq w_{L}^{*},
$$

(or both). Both inequalities hold strictly if either $\min \left\{\mu_{H}, \mu_{L}\right\}>0$ or $\max \left\{\mu_{H}, \mu_{L}\right\}>$ $\mu$ (or both).

It is thus beneficial for at least one group of labourers to abandon the joint labour union (if it does already exist) and to constitute a craft-specific labour union. Or reversely, at least one group of labourers suffers from a unification of the two professional labour unions and the formation of an encompassing union. This result holds for each group on the whole (Proposition 3) as well as for each of its members (Corollary 3) - and it may even hold for both types of labourers as Corollary 2 shows.

\section{Corner Solutions}

Finally we shall argue in this section that, in the case of joint bargains, corner solutions may well result. If this happens to occur, either of both groups is paid at its reservation wage, while the other receives a wage rate above its reservation level. To start with, 
we substitute for $\eta_{H}^{*}, \eta_{L}^{*}$ and $R^{*}$ in eqs (14) and (15), so that the Nash curves under joint bargains may be written as

$$
\left(w_{H}^{*}-f_{H}^{*}\right)\left((1-\mu) \pi^{c}-\pi^{*}\right)=0=\left(w_{L}^{*}-f_{L}^{*}\right)\left((1-\mu) \pi^{c}-\pi^{*}\right) .
$$

It follows that both conditions are fulfilled if $w_{H}^{*}$ and $w_{L}^{*}$ are set so as to guarantee

$$
\begin{array}{rll}
\pi^{*}=(1-\mu) \pi^{c} & \Leftrightarrow \quad w_{L}^{*} L^{*}+w_{H}^{*} H^{*}=Y^{*}-(1-\mu) \pi^{c} \\
& \Leftrightarrow \quad L^{*}\left(w_{L}^{*}-\bar{w}_{L}\right)+H^{*}\left(w_{H}^{*}-\bar{w}_{H}\right)=\mu \pi^{c} .
\end{array}
$$

Accordingly, under joint negotiations, the payoff of the united labour union equals a share equal to its bargaining power $\mu$ of the competitive profit, $\pi^{c}$. The joint labour union thus acquires a share of the pure economic profit, which is the higher the greater is its bargaining power. Moreover, we now become aware that in the solution there is one degree of freedom, as any pair $\left(w_{H}^{*}, w_{L}^{*}\right)$ satisfying condition $(23)$ is a solution of the bargaining problem. Let henceforth the set of these pairs be denoted by $S^{*}$. Since the right hand side of eq. (23) is constant, as $\left(H^{*}, L^{*}\right)$ is fixed at $\left(H^{c}, L^{c}\right)$, the set $S^{*}$ can conveniently be defined by $S^{*}:=\left\{\left(w_{H}^{*}, w_{L}^{*}\right) \mid w_{L}^{*} L^{c}+w_{H}^{*} H^{c}=C\right\}$, with the constant $C$ given by $C:=Y^{c}-(1-\mu) \Pi^{c}$.

In the preceding sections we scrutinized an interior solution (compare conditions (23) and (18)) assuming that both wages are set above the respective reservation wages. However, we now realise that $w_{H}^{*}$ and $w_{L}^{*}$ are not uniquely determined and that, beyond this, corner solutions may also come about in equilibrium: In this case, one group of labourers receives its reservation wage, while the other group receives a correspondingly higher wage rate. Clearly, since the bargaining solution is unique in terms of the parties' utility, all equilibrium quadruples $\left(w_{H}^{*}, w_{L}^{*}, H^{*}, L^{*}\right)$ must yield the same utility pair $\left(\psi^{*}, \pi^{*}\right):=\left(\Psi\left(w_{H}^{*}, w_{L}^{*}, H^{*}, L^{*}\right), \Pi\left(w_{H}^{*}, w_{L}^{*}, H^{*}, L^{*}\right)\right)$, so that with employment fixed at $\left(H^{*}, L^{*}\right)=\left(H^{c}, L^{c}\right)$, both parties are indifferent between any pair $\left(w_{H}^{*}, w_{L}^{*}\right)$ satisfying eq. (23). This implies that both parties' indifference curves, representing the utility levels $\left(\psi^{*}, \pi^{*}\right)$ must coincide in the $\left(w_{H}, w_{L}\right)$-space for all pairs $\left(w_{H}^{*}, w_{L}^{*}\right) \in S^{*}$. In fact, differentiating equation (23) with respect to both wage rates, we obtain

$$
\frac{d w_{H}^{*}}{d w_{L}^{*}}=-\frac{L^{*}}{H^{*}}
$$

which equals the slope of the indifference curves of both the labour union and the firms in the $\left(w_{H}, w_{L}\right)$-space. ${ }^{34}$ Consequently, both parties' indifference curves are straight lines with slope $-L^{*} / H^{*}$, for all $\left(w_{H}^{*}, w_{L}^{*}\right) \in S^{*}$. Employers and the joint labour union are both interested only in the sum of total wage payment, though with opposing signs, such that the distribution of labour cost among the two groups does not matter.

\footnotetext{
${ }^{34}$ This is a direct consequence of $\partial \Psi / \partial w_{H}=-\partial \Pi / \partial w_{H}=H$ and $\partial \Psi / \partial w_{L}=-\partial \Pi / \partial w_{L}=L$.
} 
We subsequently scrutinize the implications of these corner solutions. To this end, let us suppose for expository purpose that $w_{H}^{*}=\bar{w}_{H}=f_{H}^{*}$. Since the utility of type- $H$ labourers is reduced to their reservation wage, type- $L$ labourers and the firm divide the available profit $\pi^{c}=Y^{c}-f_{H}^{c} H^{c}-f_{L}^{c} L^{c}=Y^{*}-f_{H}^{*} H^{*}-f_{L}^{*} L^{*}$ among them according to the rule

$$
w_{L}^{*}=\mu \frac{Y^{*}-f_{H}^{*} H^{*}}{L^{*}}+(1-\mu) f_{L}^{*},
$$

or equivalently $\left(w_{L}^{*}-f_{L}^{*}\right) L^{*}=\mu \pi^{c}$. Comparing eq. (24) with eq. (15), we deduce that both conditions can only hold if $\mu=\eta_{L}^{*}=\mu /\left(1+R^{*-1}\right)$. It thus follows that $R^{*}=+\infty$, reflecting the fact that $w_{H}^{*}=\bar{w}_{H}$ - which is what we presumed initially. Similarly, if we presume $w_{L}^{*}=\bar{w}_{L}$, the $H$-type labourers and the firm divide the competitive profit among them, implying that $R^{*}$ equals zero. Hence, combining interior and corner solutions we conclude that all wage agreements in $S^{*}$ cover values of $R^{*}$ ranging over $\mathbb{R}_{+}$, while leaving the utilities of both bargaining parties unaffected.

It is clear that the group of labourers whose members merely receive their reservation wage is worse off, when compared with separate bargains, for the wage falls while employment is fixed. One might therefore expect that the second group of labourers must benefit from joint bargains if they accomplish to hold the wage of the other group at its reservation wage. However, we now show that this presumption is not necessarily true. Accordingly, we now explore whether, and if so, under which conditions one group of labourers may benefit from a corner solution under joint bargains, when compared with the outcome under separate bargains. To this end, presume w.l.o.g. that $\mu_{H} \geq \mu_{L}$ and thus $\mu \in\left[\mu_{L}, \mu_{H}\right]$. (Recall that $\mu$ is a short hand notation for some function weakly increasing $\mu:[0,1] \times[0,1] \rightarrow[0,1]$ with $\mu\left(\mu_{H}, \mu_{L}\right) \in\left[\min \left\{\mu_{H}, \mu_{L}\right\}, \max \left\{\mu_{H}, \mu_{L}\right\}\right], \forall \mu_{H}, \mu_{L} \in[0,1]$.)

Let us first consider the situation of $L$-type labourers assuming that the utility of $H$-type labourers is boiled down to their reservation utility, i. e., $w_{H}^{*}=\bar{w}_{H}=f_{H}^{*}$. For the labourers of group $L$ to be better off under $w_{H}^{*}=\bar{w}_{H}=f_{H}^{*}$, than under under separate bargains, it must be true that

$$
w_{L}^{*}>\hat{w}_{L} \Leftrightarrow \mu>\hat{\eta}_{L}\left(\mu_{H}, \mu_{L}\right):=\frac{\mu_{L}\left(1-\mu_{H}\right)}{1-\mu_{H} \mu_{L}} .
$$

As this condition is fulfilled for any pair for $\mu_{H} \geq \mu_{L}$, we obtain the following result:

Proposition 4. Let $w_{H}^{*}=\bar{w}_{H}$. Then $w_{L}^{*} \geq \hat{w}_{L}$ for all $\left(\mu_{H}, \mu_{L}\right) \in[0,1] \times[0,1]$ with $\mu_{H} \geq \mu_{L}$; and $w_{L}^{*}>\hat{w}_{L}$ whenever either $\mu>\mu_{L}$ or $\mu_{L}>0$ (or both).

Proof: Since $\hat{\eta}_{L}$ is decreasing in the first and increasing in its second argument, the function $\hat{\eta}_{L}\left(\cdot, \mu_{L}\right)$ is maximal (on $\left.\left[\mu_{L}, 1\right]\right)$ for $\mu_{H}=\mu_{L}$, with $\hat{\eta}_{L}\left(\mu_{L}, \mu_{L}\right)=\mu_{L} /(1+$ $\left.\mu_{L}\right)$. Thus $\mu>\mu_{L}$ and $\mu_{L}>0$ are both sufficient conditions for $\mu>\hat{\eta}_{L}\left(\mu_{H}, \mu_{L}\right)$. As a consequence, the weaker group of labourers is always better off under joint 
negotiations (compared to separate negotiations), if the wage of the stronger group is fixed at its reservation wage.

Let us next consider the situation of type- $H$ labourers, assuming now that $w_{L}^{*}=$ $\bar{w}_{L}=f_{L}^{*}$. For the labourers of group $H$ to be better off in this corner solution than under separate bargains, it must be true that

$$
w_{H}^{*}>\hat{w}_{H} \Leftrightarrow \mu>\hat{\eta}_{H}\left(\mu_{H}, \mu_{L}\right):=\frac{\mu_{H}\left(1-\mu_{L}\right)}{1-\mu_{H} \mu_{L}} .
$$

This condition may or may not be fulfilled. In fact, it is fulfilled if $\mu_{H}$ is close to $\mu_{L}$; but otherwise, not. In order to state this result more precisely, let, for any given value $\mu_{H} \in[0,1], \mu_{L}=\kappa\left(\mu_{H}\right)$ be the solution of $\mu\left(\mu_{H}, \mu_{L}\right)=\frac{\mu_{H}\left(1-\mu_{L}\right)}{1-\mu_{H} \mu_{L}}$. Then we have:

Proposition 5. Let $w_{L}^{*}=\bar{w}_{L}$. Then $w_{H}^{*} \geq \hat{w}_{H}$ for all $\mu_{L} \in\left[\kappa\left(\mu_{H}\right), \mu_{H}\right]$ and $w_{L}^{*}<\hat{w}_{L}$ for all $\mu_{L} \in\left[0, \kappa\left(\mu_{H}\right)\right)$.

Proof: Since $\hat{\eta}_{H}$ is decreasing in its second argument, the function $\hat{\eta}_{H}\left(\mu_{H}, \cdot\right)$ is maximal (on $\left[0, \mu_{H}\right)$ for $\mu_{L}=0$, and minimal for $\mu_{L}=\mu_{H}$, with $\hat{\eta}_{H}\left(\mu_{H}, 0\right)=\mu_{H}$ and $\hat{\eta}_{H}\left(\mu_{H}, \mu_{H}\right)=\mu_{H} /\left(1+\mu_{H}\right)$. The function $\mu:[0,1] \times[0,1] \rightarrow[0,1]$, however, is increasing in both arguments with $\mu(x, x)=x, \forall x \in[0,1]$, so that the function $\mu\left(\mu_{H}, \cdot\right)$ is increasing with $\mu\left(\mu_{H}, 0\right) \leq \mu_{H}$ and $\mu\left(\mu_{H}, \mu_{H}\right)=\mu_{H}$. Putting pieces together, since $\hat{\eta}_{H}\left(\mu_{H}, 0\right)=\mu_{H} \geq \mu\left(\mu_{H}, 0\right)$ and $\hat{\eta}_{H}\left(\mu_{H}, \mu_{H}\right)=\mu_{H} /\left(1+\mu_{H}\right) \leq \mu_{H}=\mu\left(\mu_{H}, \mu_{H}\right)$, it follows that for any $\mu_{H} \in(0,1]$ (which are the only cases of interest), both functions, $\hat{\eta}_{H}\left(\mu_{H}, \cdot\right)$ and $\mu\left(\mu_{H}, \cdot\right)$, must intersect exactly once for some $\mu_{L} \in\left(0, \mu_{H}\right)$, due to monotonicity of $\mu\left(\mu_{H}, \cdot\right)$ and strict monotonicity of $\hat{\eta}_{H}\left(\mu_{H}, \cdot\right)$.

Proposition 5 states that $\mu>\hat{\eta}_{H}\left(\mu_{H}, \mu_{L}\right)$ can never be fulfilled for some $\mu_{L}$ sufficiently close to zero; but this condition does hold for some $\mu_{H}$ sufficiently close to $\mu_{H}$. In other words, if the bargaining power of the stronger group sufficiently dominates the power of the weaker group, there is no incentive to constitute a joint labour union, even if under a joint labour union the weak group were to receive its reservation wage. Only if the difference $\mu_{H}-\mu_{L}$ becomes sufficiently small, is it beneficial for the stronger group to end up in the "favourable" corner solution under a joint labour union.

Two effects determine whether a corner solution under bargains with a joint labour union or (an interior solution under) bargains with a separate labour union yields a higher wage rate (and thus a higher wage share). Both of these effects can formally be seen by inspecting the respective Nash products, so compare the Nash product of the labour union of group $i$,

$$
\max _{w_{i}}\left[L_{i}^{c}\left(w_{i}-\bar{w}_{i}\right)\right]^{\mu_{i}}\left[Y^{c}-w_{i} L_{i}^{c}-w_{-i} L_{-i}^{c}\right]^{1-\mu_{i}},
$$

with the Nash product of the joint labour union, when $w_{-i}$ is fixed at $\bar{w}_{-i}$,

$$
\max _{w_{i}}\left[L_{i}^{c}\left(w_{i}-\bar{w}_{i}\right)\right]^{\mu}\left[Y^{c}-w_{i} L_{i}^{c}-\bar{w}_{-i} L_{-i}^{c}\right]^{1-\mu} .
$$


Then, the first effect originates from the consequences of the union unification by bringing about a modified parameter of bargaining power, so that $\mu_{i}$ is replaced by $\mu$. This effect is clearly beneficial for the weak, but detrimental for the strong group of workers, as $\mu$ is some weighted average of the pre-unification parameters of bargaining power. The second effect results from an increase in the size of the cake about which the joint labour union and the employers' federation negotiate, once the wage of the other group is fixed at the respective reservation wage.

In Section 6 we showed that there is a strong tendency for both groups of labourers to favour independent bargains over joint bargains (see Proposition 3). If however the joint labour union and the employers' federation were to agree upon a corner solution (or some outcome sufficiently close to that), the picture may change somewhat for one group: In a corner solution one group is left with its reservation utility, implying that total economic profit is divided by the other group and the firm. While the firm and the united labour union are indifferent between any solution in $S^{*}$, a corner solution is beneficial for one group of labourers if the amount which can be reaped from the other is sufficiently large, such that after sharing this with the firm, a larger wage payment is achieved than under separate bargains. While this revenue effect is always sufficiently strong for the weaker of both groups of labourers, it cannot come about, though, for the stronger group when the bargaining power of the weaker group is sufficiently close to zero. For, in this case, the strong group can appropriate only a small amount from the weak, while it would have negotiated for a substantial share of the economic rent in separate negotiations, anyway.

\section{Conclusion}

Within the last decades we observed two opposing trends in trade union formation: On the one hand, independent labour unions merged in order to constitute encompassing or industry unions; on the other hand, specialized groups of employees formed independent craft-specific labour unions, or abandoned existing tariff-unions. Due to the overwhelming economic importance of labour markets and labour market contracts, it is both a politically important, economically intriguing and theoretically challenging question whether labour unions (should) amalgamate or stand alone. In this paper we tackle this question and ask whether it is in the interest of two different groups of employees to maintain their own independent professional labour unions, or to form a joint (or encompassing) union; and if so, under which conditions.

Applying the (asymmetric) Nash bargaining solution to firm-union negotiations, we commence our analysis with an inspection of the Pareto and the (so-called) Nash curves with and without a merger. Compared with the situation under separate negotiations a merger does not affect the shape of the Pareto curves, but significantly affects the Nash curves: For a united trade union the original parameters of bargaining power of the two independent unions are replaced by a new parameter which we 
call "notional bargaining power". The parameters account for the effects a labour contract for one group imposes on the other: Firstly, there is the effect that an amalgamation of the two labour unions results in a new trade union whose bargaining power is arguably some combination of those of its constituents. Secondly, the joint labour union acknowledges that a more favourable contract on behalf of one group of labourers raises the firm's cost and thus reduces the scope for a propitious contract on behalf of the other group, an effect which is disregarded by independent unions. Both effects make the joint union to demand more moderate contracts such that the total wage bill is lower and profit is higher under negotiations with a joint union when compared with two independent unions.

As shown, the wage bill may be split arbitrarily between the two groups, for any substitution in wage rates which leaves profit unaffected also accomplishes the task to keep the encompassing unions utility constant. That is, a joint union may trade the utility of one group for benefit of the other without affecting profits. For that reason there is a continuum of equilibrium labour market contracts the firm and the joint union may negotiate for. Yet, whatever solution they choose, at least one group of labourers is worse off when compared with the bargaining outcome with independent labour unions - and under a sufficient degree of symmetry, even both will be worse off. This shows that a single group may not be wrong in suspecting that its interest may effectively be disregarded by a large encompassing union.

Equipped with these findings, we then explore the stability of a joint labour union. Assuming that transfer payments between different types of workers are not possible, an encompassing union must be regarded as unstable (if it presently exists) or as unlikely to be established (if it does not yet exist). Because at least one group of labourers is better of with an independent craft-specific union, this instability result holds true irrespective of whether we view the choice of the union structure as a non-cooperative game or as a co-operative game with non-transferable utility.

Our results are thus consistent with two central conclusions of Horn and Wolinsky (1988), p. 485 (and others): When the two types of labour are sufficiently strong complements, then in equilibrium the two types are likely to be organized in two separate unions; and when there are two independent unions their behaviour is more aggressive. The latter result explains why the "effective" bargaining power of each group tends to be lower after the merger when compared with the pre-merger level. However, our analysis does not only confirm their results, but also substantially extends them, as we employ a different equilibrium concept (efficient Nash bargains) and, more importantly, allow for some arbitrary well-behaved production function and allow for an endogenous determination of the wage rates and the employment levels of both groups of labourers.

Finally, from the firm's point of view the result is clear-cut. The profit is higher under joint negotiations than under separate negotiations with two unions. Firms 
thus favour bargaining with a joint labour union, over bargaining with independent craft-specific labour unions. To cite Horn and Wolinsky (1988), p. 493, again: ... when the two types of labour are organized separately each union can force the firm to bargain over the division of the entire surplus. In this sense the firm's surplus is bargained for twice - by each union in turn. Thus, while a firm may disapprove to negotiate with a labour union acting on behalf of all workers' interest, bargaining with two independent labour unions is even worse.

In view of the instability result of an encompassing labour union, this paper contributes to explaining the recently observed trend towards the formation small independent craft-specific unions. Clearly, our model abstracts from some important aspects such as an endogenization of the bargaining power, the self-interest of union leaders or heterogeneous preferences of workers. In particular, a consideration of noncompetitive behaviour on the output market and thus an analysis of the degree of competition on the output market on labour market negotiations may shed additional light onto the incentives for union mergers. An incorporation of these features may or may not confine this result, and, as a result, may also lead to a modification of the implied optimal policy rule for employees which recommends split-ups rather than amalgamations of labour unions. Such extensions of the present model must be left for future research, though.

\section{References}

Thorsten Bayındır-Upmann and Matthias G. Raith. Should High-Tax Countries Pursue Revenue-Neutral Ecological Tax Reforms? European Economic Review, 47: 41-60, 2003.

Thorsten Bayındır-Upmann and Matthias G. Raith. Unemployment and Pollution: Is One Policy Suited for Two Problems? The Economic Record, 81:378-393, 2005. Charles R. Bean and Peter J. Turnbull. Employment in the British Coal Industry: A Test of the Labour Demand Model. Economic Journal, 98(393):1092-1104, 1988.

Ken Binmore. Nash Bargaining Theory I, II. In K. Binmore and P. Dasgupta, editors, The Economics of Bargaining. Basil Blackwell, 1987.

Ken Binmore, Ariel Rubinstein, and Asher Wolinsky. The Nash Bargaining Solution in Economic Modelling. Rand Journal of Economics, 17:176-188, 1986.

Stefan Boeters. Green Tax Reform and Employment: The Interaction of Profit and Factor Taxes. FinanzArchiv, 60(2):222-239, 2004.

Volker Britz, P. Jean-Jacques Herings, and Arkadi Predtetchinski. Non-cooperative Support for the Asymmetric Nash Bargaining Solution. Journal of Economic Theory, 145(5):1951-1967, 2010.

James N. Brown and Orley Ashenfelter. Testing the Efficiency of Employment Contracts. Journal of Political Economy, 94(3, Part 2):S40, 1986.

Robert T. Buchanan. Merger Waves in British Unionism. Industrial Relations Journal, 2(5):37-44, 1974. 
Robert T. Buchanan. Mergers in British Unions 1949-79. Industrial Relations Journal, 3(12):40-49, 1981.

Jacques Bughin. Union-Firm Efficient Bargaining and Test of Oligopolistic Conduct. Review of Economics and Statistics, 75(3):563-567, 1993.

John T. Campling and Grant Michelson. Trade Union Mergers in British and Australian Television Broadcasting. British Journal of Industrial Relations, 35(2):215242, 1997.

Gary N. Chaison. A Note on Union Merger Trends, 1900-1978. Industrial and Labor Relations Review, 34(1):114-120, 1980.

Louis N. Christofides. Non-Nested Tests of Efficient Bargain and Labour Demand Models. Economics Letters, 32:91-96, 1990.

John Creedy and Ian M. McDonald. Models of Trade Union Behaviour: A Synthesis. The Economic Record, 67:346-359, 1991.

Carl Davidson. Multiunit Bargaining in Oligopolistic Industries. Journal of Labor Economics, 6(3):397-422, 1988.

Ralitza Dimova. Monopolistic Wages or Efficient Contracts? What Determined the Wage-Employment Bargain in Post-privatization Bulgaria?. Economics of Transition, 14(2):321-347, 2006.

Steve Dowrick. Union-Oligopoly Bargaining. Economic Journal, 99(398):1123-1142, 1989.

Steve Dowrick. Enterprise Bargaining, Union Structure and Wages. Economic Record, 69(207):393-404, 1993.

John Duggan. Non-cooperative Games Among Groups. Mimeo available from http://www.johnduggan.net, 2001.

Bernhard Ebbinghaus. Ever Larger Unions: Organisational Restructuring and its Impact on Union Confederations. Industrial Relations Journal, 34(5):446-460, 2003.

Andrea Gavosto. The British Docks: A Test of Alternative Models of Wage and Employment Determination. Labour, 11(2):225-248, 1997.

Anke Gerber and Thorsten Upmann. Bargaining Solutions at Work: Qualitative Differences in Policy Implications. Mathematical Social Sciences, 52:162-175, 2006.

Gerard Griffin and Victor Scarcebrook. Trends in Mergers of Federally Registered Unions 1904-1986. Journal of Industrial Relations, 31:257-262, 1989.

Nicole Gürtzgen. Revisiting the Impact of Union Structures on Wages: Integrating Different Dimensions of Centralization. Labour, 17(4):519-542, 2003.

Henrik Horn and Asher Wolinsky. Worker Substitutability and Patterns of Unionisation. Economic Journal, 98(391):484-497, 1988.

Byoung Heon Jun. Non-cooperative Bargaining and Union Formation. Review of Economic Studies, 56(1):59-76, 1989.

Klaus Kultti and Hannu Vartiainen. Multilateral Non-cooperative Bargaining in a General Utility Space. International Journal of Game Theory, 39(4):677-689, 2010. 
Annick Laruelle and Federico Valenciano. Noncooperative Foundations of Bargaining Power in Committees and the Shapley-Shubik Index. Games and Economic Behavior, 63(1):341-353, 2008.

Nicholas P. Lawson. Is Collective Bargaining Pareto Efficient? A Survey of the Literature. Journal of Labor Research, 32(3):282-304, 2011.

Thomas E. MaCurdy and John H. Pencavel. Testing between Competing Models of Wage and Employment Determination in Unionized Markets. Journal of Political Economy, 94(3):3-39, 1986.

Ian M. McDonald and Robert M. Solow. Wage Bargaining and Employment. American Economic Review, 71:896-908, 1981.

Eiichi Miyagawa. Subgame-Perfect Implementation of Bargaining Solutions. Games and Economic Behavior, 41(2):292-308, 2002.

Toshiji Miyakawa. Note on the Equal Split Solution in an n-Person Noncooperative Bargaining Game. Mathematical Social Sciences, 55(3):281-291, 2008.

Kim Moody. The Direction of Union Mergers in the United States: The Rise of Conglomerate Unionism. British Journal of Industrial Relations, 47(4):676-700, 2009.

Timothy Morris. Trade Union Mergers and Competition in British Banking. Industrial Relations Journal, 2(17):129-140, 1986.

John Pencavel and Bertil Holmlund. The Determination of Wages, Employment, and Work Hours in an Economy with Centralised Wage-Setting: Sweden, 1950-83. Economic Journal, 98(393):1105-1126, 1988.

Emmanuel Petrakis and Minas Vlassis. Endogenous Wage Bargaining Institutions in Oligopolistic Sectors. Economic Theory, 24(1):55-73, 2004.

Debraj Ray. A Game-Theoretic Perspective on Coalition Formation. Oxford University Press, 2007.

Per Skedinger. Employment Determination in the Swedish Wood Industry: A Test of the Labor Demand Model. Finnish Economic Papers, 5(1):27-37, 1992.

Jan Svejnar. Bargaining Power, Fear of Disagreement, and Wage Settlements: Theory and Evidence from U.S. Industry. Econometrica, 54(5):1055-1078, 1986.

Walter Trockel. Implementations of the Nash Solution Based on Its Walrasian Characterization. Economic Theory, 16(2):277-294, 2000.

Walter Trockel. A Universal Meta Bargaining Implementation of the Nash Solution. Social Choice and Welfare, 19(3):581-586, 2002.

Eric E. C. van Damme. The Nash Bargaining Solution Is Optimal. Journal of Economic Theory, 38(1):78-100, 1986.

Jeremy Waddington. Trade Union Mergers. In D. Cox, editor, Facing the Future., pages 105-146. Nottingham University Press, 1992.

Jeremy Waddington. The Trade Union Merger Process in Europe: Defensive Adjustment or Strategic Reform?. Industrial Relations Journal, 37(6):630-651, 2006. 
Paul Willman. Merger Propensity and Merger Outcomes Among British Unions, 1986-1995. Industrial Relations Journal, 27(4):331, 1996.

Bill Z. Yang. Unionized Oligopoly, Labor-Management Cooperation, and International Competitiveness. Journal of Economics (Zeitschrift fur Nationalokonomie), 62(1):33-53, 1995. 